\title{
'There is absolutely no need for dual registration'
}

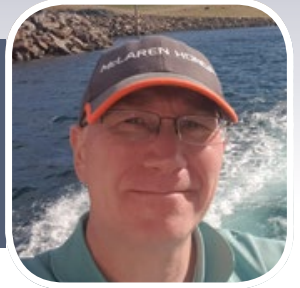

\author{
Shaun Howe, dental therapist with the Public Dental Service, NHS \\ Shetland and member of the BDJ Team reader panel, explores the \\ use of titles in use in dentistry and shares his thoughts on possible \\ alternatives for the future.
}

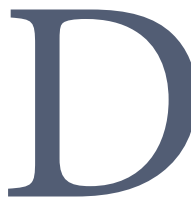

ental hygienists have been around for over 100 years, ever since Alfred Fones trained his assistant Irene

Newman in how to remove deposits off teeth to help improve oral health. In the United Kingdom, the RAF dallied with the concept in the mid to late 1920s but no formalised training was carried out until the 1940s: again, the RAF led the way. The title 'dental hygienist' was now part of the professional lexicon.

Dental therapy can trace its origins to 'dental dressers' who carried out examinations and treatment specifically on children during the First World War, but this was soon abolished after hostilities ceased. New Zealand then led the way, developing the skills of dental auxiliaries. Training in the UK began in the late 1950s and so another distinct branch of UK dentistry was born.

There has been a recent trend, mostly from dental schools, to use an unrecognised term 'hygiene therapist'. They have incorrectly argued that their students/graduates are 'dually qualified' - which is on the whole factually wrong. Many modern graduates qualify under a single qualification such as the BSc in Oral Health Sciences so are singly qualified. I shall discuss the matter of dual registration towards the end of this article.

Some of the confusion may have come from our dentist colleagues who, especially if qualified for some time, may have an archaic view of the dental therapist. Let me explain more. Dental hygienists have been able to work in general dental practice since 1974. Before this, they worked in the Armed Forces, community, prison, hospital or school settings. The transition from the restricted area of practice came much later for dental therapists but nonetheless, there were so many dentists (and to this day) that fail to understand the full scope of a dental therapist, with many still thinking that the treatment we deliver is limited to children.

It is quite true that dental therapists who qualified from the New Cross school were never trained in periodontal treatments but many subsequently added dental hygiene to their $\mathrm{CV}$ and these can be truly labelled 'dually qualified. There is some speculation that this is the reason the made up term of 'hygiene therapist' was mooted but sadly, I am unable to trace the origins of the term. The theory suggested to me was that it identified the new era of dental therapists that had been trained in periodontal
I have approached the GDC regarding dual registration and the singly qualified modern dental therapist. The answer received was far from adequate, but there is no surprise there. There is absolutely no need for dual registration. It is time it was dropped to allow my dental hygienist colleagues to be identified as a distinct group of health professionals. Those dental therapists who suggest that this distracts potential employers are misleading themselves as it just takes explanation to those that do not understand our scope.

\section{'There are two titles protected in law that}

$$
\text { only those on the GDC Register with an }
$$

appropriate qualification can use; these are dental hygienist and dental therapist. The

\section{term "hygiene therapist" appears nowhere."}

diseases and treatments over those who had gone before. Credible I guess?

But why would any of my colleagues want to use this title?

There are two titles protected in law that only those on the GDC Register with an appropriate qualification can use; these are dental hygienist and dental therapist. The term 'hygiene therapist' appears nowhere. To me personally, it is an affront. I am dually qualified and dually titled (I appear as a dental hygienist and dental therapist on the GDC register) but I choose to use only one. It is very simple: I am, in my full scope of practice, allowed to carry out all those duties I am trained and competent in. I have no need for dual titles or indeed, made up titles and in a nod of my head to the GDC, no need for dual registration.
'Hygiene Therapist' belongs in the bin with words like 'chillax' and 'amazeballs. For sure, language develops and professional titles change over time. It is possibly time that the title 'dental therapist' was revisited but it would upset me and many others should 'hygiene therapist' be adopted. Put it in the bin and call yourself the title you earned: DENTAL THERAPIST.

\section{See also:}

'But for New Cross, dentistry would be the poorer' (2008) https://www.nature.com/articles/vital888

What's in a name? (2015) https://www.nature. com/articles/bdjteam 2015149

https://doi.org/10.1038/s41407-020-0343-8 